\title{
ASSESSMENT OF DEPENDENCE OF THE HYPOGLYCEMIC EPISODES FREQUENCY ON GENDER FACTOR
}

Authors E. Makhlina, Y. Navmenova*, T. Mokhort**

SI Republican Research Centre for Radiation Medicine and Human Ecology, Gomel State Medical University*, Belarusian State Medical University**

\section{OBJECTIVES}

Assessment of the frequency of hypoglycemic episodes during daily monitoring of glucose in the subcutaneous water of women and men with type 1 diabetes mellitus.

\section{METHODS}

The study of daily dynamics of glucose has been performed with continuous glucose monitoring system (CGMS) Medtronik MINIMED company, the USA. The study involved 162 patients with type 1 diabetes mellitus. The patients were divided into 2 groups: group 1 - women with regular menstrual cycle $(n=117)$, group 2 - men $(n=$ $45)$. The groups were compared in mean age $(29,14 \pm 7,56$ years) and duration of type 1 diabetes mellitus $(10,74 \pm 7,67$ years $)$.

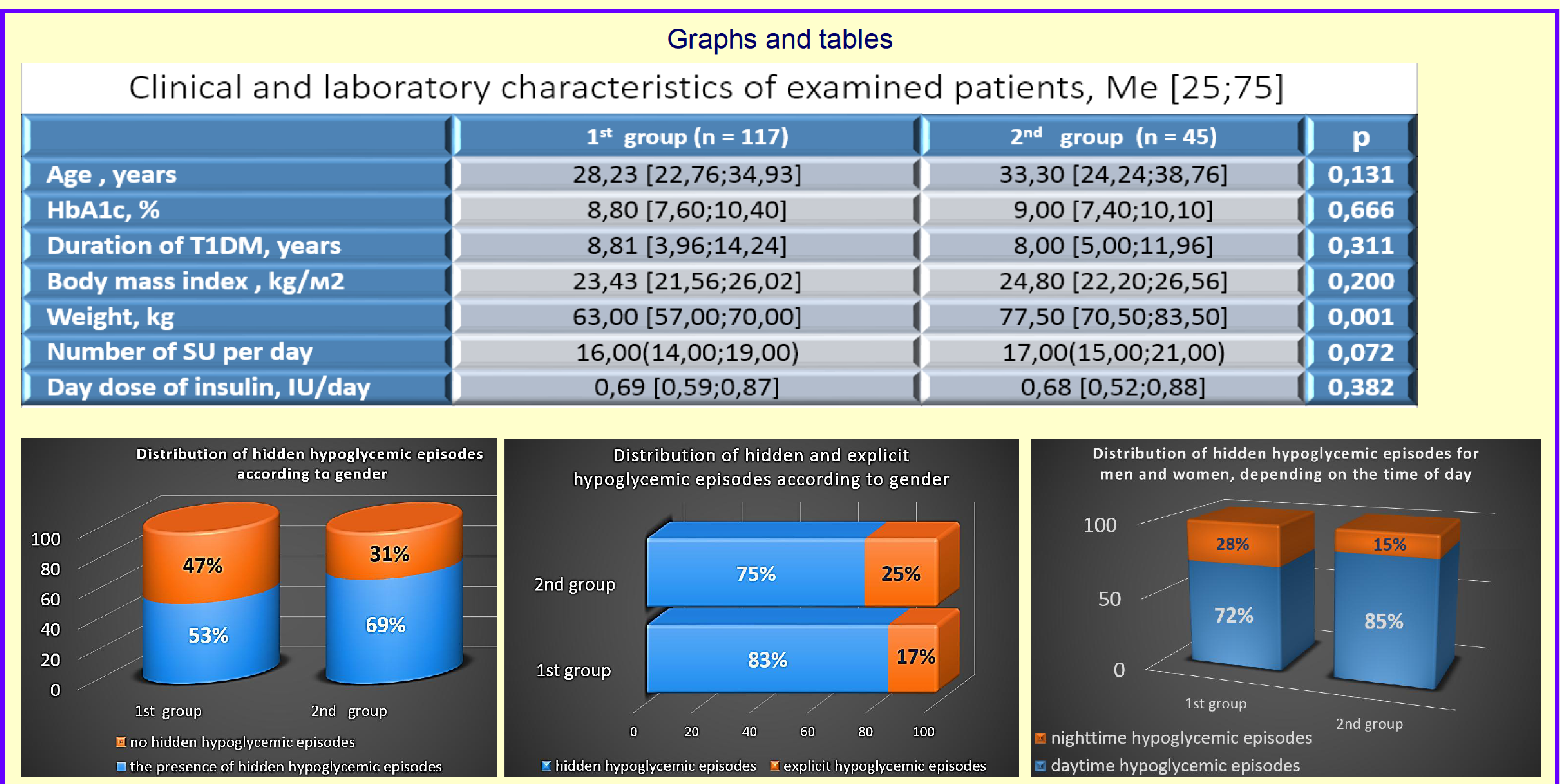

\section{RESULTS}

In the first group of women $53 \%$, registered hidden hypoglycemic episodes, and $47 \%$ were not observed $(p<0.05)$. In the second group of men $69 \%$ has been registered hidden hypoglycemic episodes, and $31 \%$ were not observed $(p<0.01)$. As for the incidence of hidden hypoglycemic episodes between the groups, the significant differences were not observed (in the first group - 53\%, in the second group - 69\%) p>0.05.

Depending on the time of day, the incidence of hidden hypoglycemic episodes (in the first group, $83 \%$ in the second group, $75 \%$ ) prevailed in comparison with explicit (in the first group, $17 \%$, in the second group, $25 \%$ ) $p<0.001$. The daytime incidence of hypoglycemic episodes in the first group was $72 \%$, in the second group was $85 \%$ in comparison with the incidence of night hypoglycemic episodes (in the first group $28 \%$, in the second group $15 \%$ ), $p<0,05$.

\section{CONCLUSIONS}

1. Regardless of gender, the bulk of the cases occurred in hidden hypoglycemic episodes compared with explicit ones.

2. The incidence of hidden day-time hypoglycemic episodes was prevailed over the night incidence of hypoglycemic episodes, regardless of gender.

3. The incidence of hidden hypoglycemic episodes does not depend on gender. 